\title{
COMMUNITY EDUCATION RELATED TO THE USE OF FAMILY MEDICINE PLANTS IN VILLAGE GIRIAWAS, GARUT DISTRICT, JAWA BARAT
}

\author{
Framesti Frisma Sriarumtias \\ Program Studi S1 Farmasi, Fakultas Matematika dan Ilmu Pengetahuan Alam Universitas Garut \\ *E-mail: framesti@uniga.ac.id
}

\begin{abstract}
Community service this time aims to motivate the community to utilize the house yard into land for family medicinal plants (TOGA). The method used is in the form of counseling and data collection on plants that are usually planted by residents. Counseling is done by lecturing by distributing reading material in the form of material handouts delivered. And data collection is done by discussing with the people who attended the event. The target of this service is the women of recitation in Giri Ayu Village, Giriawas Village, Garut Regency, West Java. The results of this community service are able to understand related to the utilization of family medicinal plants that can be used for prevention.
\end{abstract}

Keywords : Counseling; Family Medicinal Plant; Preventive

\begin{abstract}
Abstrak
Pengabdian kepada masyarakat kali ini bertujuan untuk memotivasi masyarakat agar memanfaatkan pekarangan rumah menjadi lahan untuk Tanaman Obat keluarga (TOGA). Metode yang dilakukan yaitu berupa penyuluhan dan pendataan tanaman yang biasa ditanam oleh warga. Penyuluhan dilakukan dengan cara ceramah dengan membagikan bahan bacaan berupa handout materi yang disampaikan. Serta pendataan dilakukan dengan cara berdiskusi dengan masyarakat yang menghadiri acara tersebut. Sasaran dari pengabdian ini yaitu ibu-ibu pengajian di Kampung Giri Ayu, Desa Giriawas, Kabupaten Garut, Jawa Barat. Hasil dari pengabdian ini masyakat mampu memahami terkait pemanfaatan Tanaman Obat keluarga yang bisa digunakan untuk preventif.
\end{abstract}

Kata Kunci: Penyuluhan; Preventif; Tanaman Obat Keluarga

\section{Article Info:}

Received 13 Juni 2020

Accepted 15 Juli 2020

Available online 31 Agustus 2020

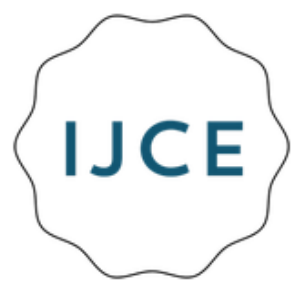




\section{PENDAHULUAN}

Pemanfaatan obat tradisional yang mengacu pada penggunaan secara empiris masih banyak dilakukan oleh masyarakat. Penguunaan obat tradisional semakin meningkat dengan adanya tren back to nature. Banyak bahan obat tradisonal yang beredar dipasaran, mulai dari hanya dalam bentuk simplisia sampai diolah kedalam bentuk sediaan farmasi dengan nilai teknologi yang tinggi, seperti dibuat nanoteknologi. Masyarakat beralih dari obat sintesis ke obat herbal karena klaim efek samping yang ditimbulkan oleh obat-obat sintetis. Tetapi sayangnya belum banyak masyarakat yang mengenai terkait aktivitas secara ilmiah dari suatu tanaman obat. Masyarakat hanya mengenal obat tradisional berdasarkan penggunaan dari nenek moyang secara empiris. Sehingga perlu dilakukan penyuluhan terkait pendataan tanaman obat, serta kedepannya dilakukan penanaman apotek hidup yang berisi tanaman obat keluarga (TOGA) disamping itu belum meratanya sarana kesehatan juga mahalnya harga obat [1].

Rumusan masalah pada pengabdian kali ini yaitu bagaimana cara menyampaikan kepada masyarakat terkait pentinya mengelompokan penanaman tanaman sesuai fungsinya. Kebanyakan masyarakat menanam tanaman obat sembarangan, sehingga tidak banyak yang mengetahui bahwa tanaman tersebut memiliki efektivitas untuk memelihara ketahanan tubuh. Tujuan Umum kegiatan ini untuk melaksanakan program kegiatan Pengabdian Kepada Masyarakat Program Studi Farmasi Fakultas MIPA, Universitas Garut. Tujuan Khusus adalah untuk mengedukasi masyarakat tentang tanaman obat keluarga (TOGA), mengedukasi masyarakat untuk bisa menanam tanaman obat keluarga dalam bentuk apotek hidup, memberikan informasi tentang bahan alami yang bisa digunakan untuk perawatan Kesehatan.

Diharapkan manfaat dari penyuluhan ini untuk memberikan pengetahuan dasar bagi masyarakat terutama ibu-ibu rumah tangga agar bisa memanfaatkan pekarangan rumah menjadi apotek hidup. Selain itu diharapkan dengan adanya penyuluhan ini bisa menjalin tali silaturahmi serta kemitraan antara Prodi Farmasi FMIPA Uniga dengan desa Giriawas, Cikajang.

\section{METODE}

Sasaran pada pengabdian kali ini yaitu Ibu-ibu PKK Desa Cidatar kecamatan Cisurupan. Pengabdian ini dilaksanakan pada hari Sabtu, tanggal 24 Agustus 2019 pada pukul 13.00 16.00 WIB di Mesjid Kp. Giri Ayu Desa Giriawas, Kecamatan Cikajang, Kabupaten Garut, Jawa Barat. Metode yang digunakan yaitu berupa penyuluhan materi serta tanya jawab.

Kegiatan pengabdian masyarakat "Edukasi Masyarakat terkait Tanaman Obat Keluarga (TOGA)" dilaksanakan dengan menggunakan beberapa metode, yaitu: (a) pemberian materi ceramah tentang tanaman obat dengan menggunakan LCD proyektor, (b) pendataan tanaman obat di rumah warga dengan cara tanya jawab, dan (c) diskusi dan tanya jawab. [2]

Penyuluhan dilakukan dengan metode ceramah dan dilanjutkan dengan diskusi. Materi penyuluhan terdiri dari pengertian tentang TOGA, jenis-jenis tanaman obat yang dapat dibudidayakan di lahan pekarangan, serta penanganan panen dan pasca panen. Setelah selesai penyuluhan dilakukan lagi wawancara untuk apakah ada peningkatan pengetahuan para peserta. Berdasarkan. [3]

\section{HASIL DAN PEMBAHASAN}

Penyuluhan telah dilakukan di Mesjid Kp. Giri Ayu Desa Giriawas, Kabupaten Garut, Jawa Barat. Kegiatan pengabdian ini berbentuk penyuluhan dengan cara memberikan penjelasan materi terkait tanaman obat. Jumlah peserta yang hadir yaitu sebanyak 20 orang. Dalam penentuan lokasi penyuluhan ini Mahasiswa mengunjungi kantor Kepala Desa untuk melakukan diskusi dengan apparat terkait mengenai lokasi pelaksanaan penyuluhan. Maka 
dipilihlah Mesjid Kp. Giri Ayu sebagai tempat dilaksanakannya penyuluhan, hal ini dikarenakan akses yang mudah karena berada di pinggir jalan besar, serta pada waktu tersebut merupakan jadwan pengajian rutin ibu-ibu di kampung tersebut, sehingga tidak memerlukan sosialisasi. Sehingga diharapkan masyarakat bisa dengan mudah mendatangi lokasi tersebut. [2]

Mahasiswa memastikan semua sudah berjalan sesuai dengan apa yang sudah dirancang. Memeriksa fasilitas berupa laptop, proyektor serta sound system guna membuat acara ini berjalan dengan lancar. Perwakilan mahasiswa menyebar undangan kepada warga disekitar Mesjid Kp. Giri Ayu.

Peserta begitu antusias dalam mengikuti acara penyampaian materi dan proses pendataan tanaman di pekarangan rumah. Hal ini dikarenakan belum pernah ada penyuluhan terkait pemanfaatan TOGA yang baik, hal ini ditunjukan dengan beberapa pertanyaan yang muncul dari peserta. Data tanaman selama pelaksanaan kegiatan ditunjukan di tabel 1.

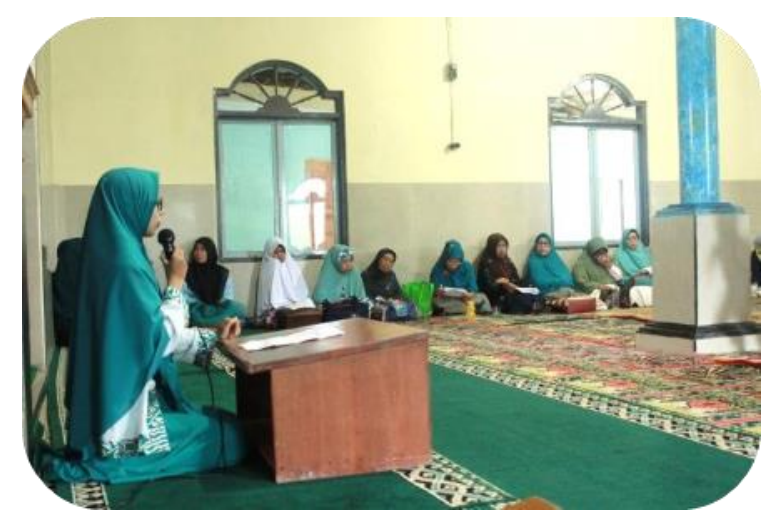

Gambar 1 Proses Pemberian Materi

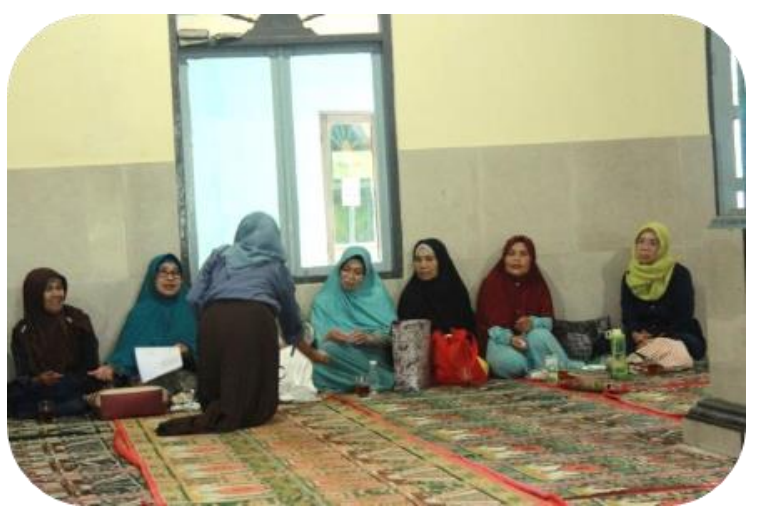

Gambar 2 Proses pendataan tanaman obat

Tabel 1 Daftar Tanaman Obat Keluarga di Kp. Giri Ayu

\begin{tabular}{lrrr}
\hline Nama & Nama Lokal & Nama Ilmiah & \multicolumn{1}{c}{ Manfaat } \\
\hline Bandotan & $\begin{array}{r}\text { Babandotan atau } \\
\text { babadotan (sunda), } \\
\text { wedusan (Jawa) }\end{array}$ & $\begin{array}{r}\text { Ageratum } \\
\text { conyzoides }\end{array}$ & $\begin{array}{r}\text { Antibakteri, antipiretik, } \\
\text { antidiabetes, antiseptik, } \\
\text { penyembuh luka dan obat } \\
\text { wasir[4] }\end{array}$ \\
\hline Binahong & Piahong & $\begin{array}{r}\text { Anredera } \\
\text { cordifolia }\end{array}$ & Obat wasir, antibakteri \\
& & & {$[5][6]$} \\
\hline
\end{tabular}




\begin{tabular}{|c|c|c|c|}
\hline Ciplukan & $\begin{array}{r}\text { Ceplukan (jawa), } \\
\text { Cecendet (Sunda), } \\
\text { Yor-yoran } \\
\text { (Madura), } \\
\text { Keceplokan (Bali), } \\
\text { Leletokan } \\
\text { (Minahasa) }\end{array}$ & $\begin{array}{l}\text { Physalis } \\
\text { angulata }\end{array}$ & $\begin{array}{r}\text { Antihiperglikemik, } \\
\text { antibakteri, antivirus, } \\
\text { imunostimulan dan } \\
\text { imunosupresan } \\
\text { (imunomodulator), } \\
\text { antiinflamasi, antioksidan } \\
\text { dan sitotoksik. [7], [8] }\end{array}$ \\
\hline Daun Ungu & $\begin{array}{r}\text { Handeleum } \\
\text { (Sunda), daun } \\
\text { wungu (Jawa), } \\
\text { Karotong } \\
\text { (Madura), daun } \\
\text { putri (Ambon) }\end{array}$ & $\begin{array}{r}\text { Graptophyllum } \\
\text { pictum }\end{array}$ & $\begin{array}{r}\text { Antiinflamasi, antidiabetes, } \\
\text { pengobatan wasir, } \\
\text { mengobati batu ginjal, } \\
\text { mengobati hepatitis.[9] }\end{array}$ \\
\hline Jahe & $\begin{array}{r}\text { Jahi (Lampung), } \\
\text { laia (Makassar), } \\
\text { Jahe (Sunda), Jae } \\
\text { (Jawa), jhai } \\
\text { (Madura), tipakan } \\
\text { (Banjarmasin) }\end{array}$ & $\begin{array}{l}\text { Zingiber } \\
\text { officinale }\end{array}$ & $\begin{array}{r}\text { Antivirus, imunostimulan, } \\
\text { antibakteri, antiinlamasi, } \\
\text { antioksidan, membantu } \\
\text { menurunkan tekanan darah, } \\
\text { mengurangi mual dan } \\
\text { muntah.[10], [11] }\end{array}$ \\
\hline Kelor & Kelor & Moringa oleifera & $\begin{array}{l}\text { Antiinflamasi, antikanker, } \\
\text { antianemia [12], [13] }\end{array}$ \\
\hline Kencur & $\begin{array}{r}\text { Cikur (Sunda), } \\
\text { ceuko (Aceh), } \\
\text { kencor (Madura), } \\
\text { sukung (Melayu) }\end{array}$ & $\begin{array}{r}\text { Kaempferia } \\
\text { galanga }\end{array}$ & $\begin{array}{l}\text { Antiinflamasi, analgetik, } \\
\text { antioksidan, antibakteri, } \\
\text { stimulant [14]-[18] }\end{array}$ \\
\hline Kiolod & $\begin{array}{r}\text { Ki tolod, daun } \\
\text { tolod (Sunda), } \\
\text { Kendali, } \\
\text { sangkobab (Jawa) }\end{array}$ & Istoma longiflora & $\begin{array}{l}\text { Antiradang, anti kanker, } \\
\text { antibakteri [19], [20] }\end{array}$ \\
\hline Kunyit & $\begin{array}{r}\text { Kakunye } \\
\text { (Enggano), Kuning } \\
\text { (Gayo), Hunik } \\
\text { (Batak), Kunyit } \\
\text { (Lampung), Kunyir } \\
\text { (Sunda), Kunir } \\
\text { (Jawa Tengah), } \\
\text { Temo Koneng } \\
\text { (Madura) }\end{array}$ & Curcuma longa & $\begin{array}{l}\text { Antikoagulan, antiedemik, } \\
\text { menurunkan tekanan darah, } \\
\text { obat malaria, obat cacing, } \\
\text { obat sakit perut, stimulant, } \\
\text { mengobati keseleo, memar, } \\
\text { rematik, antihepatotoksik, } \\
\text { enthelmintik, analgetik, } \\
\text { antiinflamasi, antioksidan } \\
\text { meredakan batuk, } \\
\text { antikanker dan antikejang. } \\
{[21][22][23][24]}\end{array}$ \\
\hline Leunca & $\begin{array}{l}\text { Leunca (Sunda), } \\
\text { Ranti (Jawa), Anti } \\
\text { bobosa (Maluku) }\end{array}$ & $\begin{array}{l}\text { Solanum } \\
\text { ningrum }\end{array}$ & $\begin{array}{r}\text { Antibakteri, antiinflamasi, } \\
\text { antidisentri, ulcerogenic, } \\
\text { antimalaria, antipiretik, } \\
\text { anthelmintik.[25] }\end{array}$ \\
\hline Seledri & $\begin{array}{l}\text { Saladri (Sunda), } \\
\text { Seledri (Jawa) }\end{array}$ & $\begin{array}{r}\text { Apium } \\
\text { graveolens }\end{array}$ & $\begin{array}{r}\text { Pemacu enzim pencernaan, } \\
\text { penambah nafsu makan, } \\
\text { peluruh air seni, penurun } \\
\text { tekanan darah, obat } \\
\text { rematik. [26], [27] }\end{array}$ \\
\hline
\end{tabular}




\begin{tabular}{lrrr}
\hline Serai & $\begin{array}{r}\text { Sereh (Jawa, } \\
\text { Sunda), Sere } \\
\text { (Jawa), Serai } \\
\text { (Sumatera) }\end{array}$ & $\begin{array}{r}\text { Cymbopogon } \\
\text { citratus }\end{array}$ & $\begin{array}{r}\text { Antibakteri, Insektisida, } \\
\text { obat kumur [10], [28] }\end{array}$ \\
\hline Sirih Hijau & & \\
\hline Ranub (Aceh), & Piper batle & $\begin{array}{r}\text { Antibakteri, antioksidan, } \\
\text { fungisida, antijamur, }\end{array}$ \\
sereh (Gayo), & & menghilangkan bau badan, \\
Seureuh (Sunda), & hemostatik, menghentikan \\
Sere (Madura), & pendarahan, analgetik [29], \\
Uwit (Dayak), & [30][10], [29], [30] \\
\hline
\end{tabular}

Penyuluhan dilakukan dengan metode ceramah dan dilanjutkan dengan diskusi. Materi penyuluhan terdiri dari pengertian tentang TOGA, jenis-jenis tanaman obat yang bisa dibudidayakan di lahan pekarangan. Setelah dilaksanakan penyuluhan dilakukan wawancara untuk mengetahui peningkatan pengetahuan para peserta. Penyuluhanini baru dilakukan satu kali sehingga tidak akan berpengaruh nyata pada peningkatan pengetahuan peserta. Perlu dilakukan penyuluhan lanjutan terkait bagaimana cara melakukan budidaya pada tanaman obat keluarga dan perlu melakukan praktek pembuatan apotek hidup [3][29] [30].

\section{KESIMPULAN DAN SARAN}

Masyarakat belum memahami secara benar terkait pemanfaatan tanaman obat keluarga sehingga tanaman obat keluarga tumbuh sembarangan di pekarangan rumah warga.

\section{REFERENSI}

[1] S. Sahidin, W. Wahyuni, M. Kamaluddin, and S. Suaib, "Tanaman Obat Keluarga (TOGA) dan Pemanfaatannya Sebagai Penunjang Kesehatan Masyarakat di Desa Sindangkasih," Pharmauho J. Farm. Sains, dan Kesehat., vol. 4, no. 2, pp. 2-4, 2019, doi: 10.33772/pharmauho.v4i2.6276.

[2] T. Rusdiana, N. A. Putriana, I. Sopyan, D. Gozali, and P. Husni, "Pemberian Pemahaman Mengenai Sediaan Herbal yang Berfungsi untuk Pemeliharaan Kesehatan Jantung dan Ginjal di desa Cibeusi, Sumedang, Jawa Barat," J. Pengabdi. Kpd. Masy., vol. 4, no. 6, pp. 129-132, 2019.

[3] U. Trisnaningsih, S. Wahyuni, and S. Nur, "Pemanfaatan Lahan Pekarangan Dengan Tanaman Obat Keluarga," JPPM (Jurnal Pengabdi. dan Pemberdaya. Masyarakat), vol. 3, no. 2, p. 259, 2019, doi: 10.30595/jppm.v3i2.4554.

[4] T. Rusdiana, N. A. Putriana, I. Sopyan, D. Gozali, and P. Husni, "Pemberian Pemahaman Mengenai Sediaan herbal yang Berfungsi untuk Pemeliharaan Kesehatan jantung dan Ginjal di Desa Cibeusi, Sumedang, Jawa Barat," J. Pengabdi. Kpd. Masy., vol. 4, no. 6, pp. 139-141, 2019.

[5] S. A. Atisha and S. R. Mita, "Review: Herba Bandotan (Ageratum conyzoides L) Sebagai Pengobatan Luka Terbuka," Farmaka Suplemen, vol. 16, no. 3, pp. 116-121, 2018.

[6] G. R. A. Kartika, S. Andayani, and S. Soelistyowati, "Potensi Ekstrak Daun Binahong (Anredera cordifolia) Sebagai Penghambat Bakteri Vibrio harveyi," J. Mar. Aquat. Sci., vol. 2, no. 2, p. 49, 2016, doi: 10.24843/jmas.2016.v2.i02.49-53.

[7] Isniyetti, "Isolasi dan Uji Antibakteri Flavanoid Dari Daun Ciplukan (Physalis minima Linn)," Curr. Top. Microbiol. Immunol., vol. 284, pp. 99-119, 2004.

[8] S. Luliana, R. Susanti, and E. Agustina, "Antiinflammatory Activity Test of Aqueous Extracts Herb of Ciplukan (Physalis angulata L.) in Caragenan Inducted Wistar Rat (Rattus norvegicus L.)," Maj. Obat Tradis., vol. 22, no. 3, p. 199, 2017, doi: 


\section{$10.22146 /$ mot.31556.}

[9] G. L. Griff, “Aktivitas Antioksidan Dari Ekstrak Etanol Daun Ungu,” vol. 5, pp. 145$151,2017$.

[10] A. D. Rizkita, "Efektivitas Antibakteri Ekstrak Daun Sereh Wangi, Sirih Hijau, Dan Jahe Merah Terhadap Pertumbuhan Streptococcus Mutans," Semin. Nas. Sains dan Teknol., no. November 2017, pp. 1-2, 2017.

[11] S. Munda, P. Saikia, and M. Lal, "Chemical composition and biological activity of essential oil of Kaempferia galanga: A review," J. Essent. Oil Res., vol. 30, no. 5, pp. 303-308, 2018, doi: 10.1080/10412905.2018.1486240.

[12] Z. Abidin, U. Khaeriah, Z. Zuhrina, M. Pratama, and M. Baits, "Tyrosinase Inhibitor Activity Measurement of Crude and Purified Extract of Moringa Leaves (Moringa oleifera L.)," Indones. J. Pharm. Sci. Technol., vol. 1, no. 1, 2019, doi: 10.24198/IJPST.V1I1.19152.

[13] M. Tahir, N. Hikmah, and Rahmawati, "Analisis Kandungan Vitamin C dan $\beta$ - Karoten dalam Daun Kelor (Moringa oleifra Lam.) dengan Metode Spektrofotometri UV-VIS," J. Fitofarmaka Indones., vol. 3, no. 1, pp. 135-140, 2014.

[14] H. Riasari, R. Rachmaniar, and S. Wahyuni, "Evaluation Patch of Rhizoma Extract Kencur ( Kaempferia galanga L .) as Anti-Inflammatory with Enhancer Evaluasi Sediaan Plester dari Ekstrak Rimpang Kencur ( Kaempferia galanga L .) sebagai AntiInflamasi dengan Penambahan Peningkat Penetrasi," Indones. J. Pharm. Sci. Technol., vol. 6, no. 2, pp. 59-64, 2019.

[15] S. M. Soleh, "Karakteristik Morfologi Tanaman Kencur (Kaempferia Galanga L.) dan Aktivitas Farmakologi," Farmaka, vol. 17, no. 2, pp. 256-262, 2019.

[16] S. Megantara, F. Farmasi, U. Padjadjaran, and A. Farmakologi, "Karakteristik Morfologi Tanaman Kencur (Kaempferia Galanga L.) dan aktivitas Farmakologi," Farmaka, vol. 17, no. 2, pp. 256-262, 2019.

[17] B. Yunianto, T. Lestari, and A. Winarso, "Aktivitas Antibakteri Salep dengan Bahan Aktif Ekstrak Kunyit, Kencur dan Temugiring terhadap Bakteri Staphylococcus aureus," J. Kebidanan Dan Kesehat. Tradis., vol. 2, no. 2, pp. 60-65, 2017.

[18] D. Lakshmanan et al., "Ethyl p-methoxycinnamate isolated from a traditional antituberculosis medicinal herb inhibits drug resistant strains of Mycobacterium tuberculosis in vitro," Fitoterapia, vol. 82, no. 5, pp. 757-761, 2011, doi: 10.1016/j.fitote.2011.03.006.

[19] H. Arifin, T. I. Alwi, O. Aisyahharma, and D. A. Juwita, "Kajian Efek Analgetik dan Toksisitas Subakut Dari Ekstrak Etanol Daun Kitolod (Isotoma longiflora L.) Pada Mencit Putih Jantan," JSFK (Jurnal Sains Farm. Klin., vol. 5, no. 2, pp. 112-118, 2018, doi: 10.25077/JSFK.5.2.112-118.2018.

[20] E. Malik and M. Dewi, "Pengaruh Perasan Daun Kitolod ( Isotoma longiflora ) Terhadap Daya Hambat Pertumbuhan Staphylococcus aureus," Farmasetis, vol. 3, no. 2, pp. 3741, 2014.

[21] F. F. Sriarumtias and N. Auliasari, "Splash mask formulation of tangerine ( Citrus reticulata Blanco .) peel extract and turmeric ( Curcuma longa $\mathrm{L}$ ) extract as a whitening agent," Int. J. Res. Dermatology, vol. 6, no. 3, pp. 341-346, 2020.

[22] H. Mirzaei, A. Shakeri, B. Rashidi, A. Jalili, Z. Banikazemi, and A. Sahebkar, "Review : Phytosomal curcumin: A review of pharmacokinetic, experimental and clinical studies,"

Biomed. Pharmacother., vol. 85, pp. 102-112, 2017, doi: 10.1016/j.biopha.2016.11.098.

[23] S. A, H. A, and Hegde Prakash L, "Pharmacological activities of wild turmeric (Curcuma aromatica Salisb): a review," J. Pharmacogn. Phytochem., vol. 3, no. 5, pp. $1-4,2015$. 
[24] F. F. Sriarumtias, F. N. Nafisah, and D. Gozali, "Splash Mask Formulation of Tangerine ( Citrus reticulata Blanco .) Peel extract as an antioxidant," J. Ilm. Farm. Bahari, vol. 10, no. 2, pp. 205-219, 2019.

[25] R. T. Kandita, R. Aisyah, and W. B. Putri, "Uji Efektivitas Ekstrak Buah Leunca (Solanum Nigrum L.) Sebagai Insektisida Terhadap Nyamuk Aedes Aegypti Dan Anopheles Aconitus," Biomedika, vol. 7, no. 2, pp. 35-42, 2015, doi: 10.23917/biomedika.v7i2.1898.

[26] M. Mappasomba, M. H. Malaka, R. Hamsidi, L. O. M. A. Zulbayu, and S. Sahidin, "Aktivitas Antimikroba dan Skrining Fitokimia Beberapa Tanaman Berkhasiat Obat di Kota Kendari," Pharmauho J. Farm. Sains, dan Kesehat., vol. 6, no. 1, p. 20, 2020, doi: 10.33772/pharmauho.v6i1.11445.

[27] F. M. Syahidah and R. Sulistiyaningsih, "Potensi Seledri (Apium graveolens) Untuk Pengobatan : Review Article," Farmaka, vol. 16, no. 1, pp. 55-62, 2018.

[28] R. A. Khasanah, E. Budiyanto, and N. Widiani, "Pemanfaatan Ekstrak Sereh (Chymbopogon Nardus L.)Sebagai Alternatif Anti Bakteri Staphylococcusepidermidis Pada Deodoran Parfume Spray," Pelita - J. Penelit. Mhs. UNY, vol. 0, no. 1, pp. 1-9, 2011.

[29] Bustanussalam, D. Apriasi, E. Suhardi, and D. Jaenudin, "Efektivitas Antibakteri Ekstrak Daun Sirih (Piper betle Linn) terhadap Staphylococcus aureus ATC 25923," J. Chem. Inf. Model., vol. 53, no. 9, pp. 1689-1699, 2019, doi: 10.1017/CBO9781107415324.004.

[30] L. Nurdianti, W. . Annissya, Y. . Pamela, E. Novianti, M. Audina, and E. Kurniasari, "Formulasi Sediaan Pasta Gigi Herbal Kombinasi Ekstrak Daun Sirih ( Piper betle ) dan Kulit Jeruk Lemon ( Citrus limon burm f.) sebagai pemutih dan antiseptik pada gigi," $J$. Kesehat. Bakti Tunas Husada, vol. 16, no. 1, pp. 177-187, 2016. 